\title{
Classification of Maghrebi camels (Camelus dromedarius) according to their tribal affiliation and body traits in southern Tunisia
}

\author{
Mohamed Chniter ${ }^{1 *}$, Mohamed Hammadi ${ }^{1}$, Touhami Khorchani ${ }^{1}$, Riadh Krit ${ }^{3}$, Abdelkader Benwahada ${ }^{3}$ \\ and Mohamed Ben Hamouda ${ }^{2}$ \\ ${ }^{1}$ Laboratoire d'Elevage and Faune Sauvage, Institut des Régions Arides, Médenine, Tunisia \\ ${ }^{2}$ Institution de la Recherche et de l'Enseignement Supérieurs Agricoles, Tunis, Tunisia \\ ${ }^{3}$ Office de l'Elevage et des Pâturages, Tunis, Tunisia
}

\begin{abstract}
Five groups of Maghrebi camels have been identified in southern Tunisia according to their tribal affiliation: the Ourdhaoui Médenine in Tawazins tribe, the Ourdhaoui Tataouine in Oudarna tribe, the Guiloufi in Beni Guilouf tribe from Kébili, the Gueoudi at Ouled Gharib tribe from Kébili and the Merzougui in the Marazigues tribe from Kébili. The identification of these groups was achieved by recording nine body measurements (length of the body, length of the neck, thoracic girth, abdominal circumference, height at the hump, height at the withers, width between shoulders, length of the anterior limb and the length of the tool) from a total of 304 female camels (age $\geq 6$ years). Positive correlation was observed between the height at the hump and height at the withers, the thoracic girth and the abdominal circumference, the length of the body and the length of the neck. However, the length of the tail showed a negative correlation with the abdominal circumference and the height at the withers. Gueoudi, Guiloufi and Merzougui camel groups had the higher body length and the higher abdominal circumference compared to Ourdhaoui Médenine group of camels. Accordingly, Guiloufi, Merzougui and Ourdhaoui Tataouine camel groups had the higher thoracic girth and the higher height at the withers in comparison with Ourdhaoui Médenine. Ourdhaoui Médenine and Ourdhaoui Tataouine camel groups had the higher tail length compared to Gueoudi, Guiloufi and Merzougui camel groups. The clustering of the five groups allowed describing three main classes of Maghrebi camel including the big, medium and small size Maghrebi camels. According to the coat color, six vernacular names were identified included Chagra, Chaâla, Safra, Hajla, Hamra and Zarga. The quality of the hair was on majority rough and thick, that way the female camel was named Nagga Chalfi. One small proportion was attributed for the females that had sleek and heavy hair which were named Nagga Khawar.
\end{abstract}

Key words: Maghrebi camels, Tribal affiliation, Body measurements, Hair quality, Southern Tunisia

\section{Introduction}

Across the world, there were some reports done on the phenotypic diversity of camel populations, like those of Hülsebusch and Kaufmann (2002) in Northern Kenya, Ishag et al. (2011) in Sudan, Faye et al. (2011) and Abdallah and Faye (2012) in Saudi Arabia. Body measurements revealed clear morphological differences among the local camel population (Hülsebusch and Kaufmann, 2002). A recent phenotypic classification study of Saudi

Received 17 December 2012; Revised 01 February 2013; Accepted 08 February 2013; Published Online 01 June 2013

*Corresponding Author

Mohamed Chniter

Laboratoire d'Elevage and Faune Sauvage, Institut des Régions Arides, Médenine 4100, Tunisia

Email: mchniter@gmail.com; Chniter2005@yahoo.fr
Arabian camel using body measurements revealed 4 types of female camel conformation, 2 breeds and six groups of males (Abdallah and Faye, 2012). The color is a common character used for camel's classification. Based on their coat color, three main breeds of Saudi camels were distinguished, namely Magaheem, Magateer and Al-Homr or Al-Sofr (Wardeh, 1991). Accordingly, Abdallah and Faye (2012) reported that Saudi Arabia camels can include twelve camel phenotypes breeds.

In Tunisia, there are some 1,00,000 camels reared in the arid and desert zones where more than $83 \%$ of these camels are found in Tataouine, Kébili and Médenine Governorates (Hammadi, 2003; Sghaier and Moslah, 2004). Despite their significance number, there is relatively limited information available on their genetic diversity (Ben Salah et al., 2009; Ould Ahmed et al., 2010) 
and no clear classification exists, but generally they can be classified according to habitat and function. Two groups of dromedary camels are documented in Tunisia named camel of Tell region and camel of River region. Otherwise, four groups of camel breeders where reported: camel of the South, camel of the Cap-Bon, camel of Sahel and camel of Kairouan (FAO and UNDP, 2000). However, classification on other parameters as the general conformation and body measurements was not clearly described for Maghrebi camels elevated in the arid region of Tunisia. The objective of the current study was to investigate differences of body measurements in relation with the different groups in female Maghrebi camels in Southern Tunisia.

\section{Materials and Methods \\ Study area}

The study, which lasted 9 months from June to February, was achieved in the Southern Tunisia (Figure 1). Southern Tunisia is a transitional region towards the Sahara and includes low plains spreading south of the high steppes, from the Algerian border to the Gulf of Gabès. It can be divided in Matmata Mountain, Jeffara, Dahars and Nefzaoua regions. The Matmata Mountain is small ranges reaching up to $600 \mathrm{~m}$ in elevation, enclosed in vast flat stretches of land. The Jeffara region in south-eastern Tunisia is the most southern pastoral region. It lies on the northern fringe of the Sahara desert and has all the features of an arid region and received an annual rainfall between 150 and 200 $\mathrm{mm}$. The Dahars region is characterized by the scarcity of water. It is occasionally inhabited by pastoralists and represents a very important grass reservoir to which many camel flocks from bordering regions move during wet period. The Nefzaoua region is situated in the southwest of Tunisia under arid climatic conditions where the annual mean precipitation is $100 \mathrm{~mm}$ and the temperature exceeds $40^{\circ} \mathrm{C}$ in summer (Belloumi et al., 2006).

In these regions, the extensive livestock breeding stills traditional and is the most common breeding system among small and medium holders that use the local breeds of sheep, goat and camels and make use, above all, of the natural vegetation without any form of management. During autumn season, camels grazed salt pasture (Sebkha) and watered from well once each two days depended mainly on the water contained in browsing plants. In spring, all herds of camels was returned towards the pasture of Dahars and did not watering during the period of transhumance. Whereas in the dry season, the camels were watered from well water once in a week and the food was added for animals.

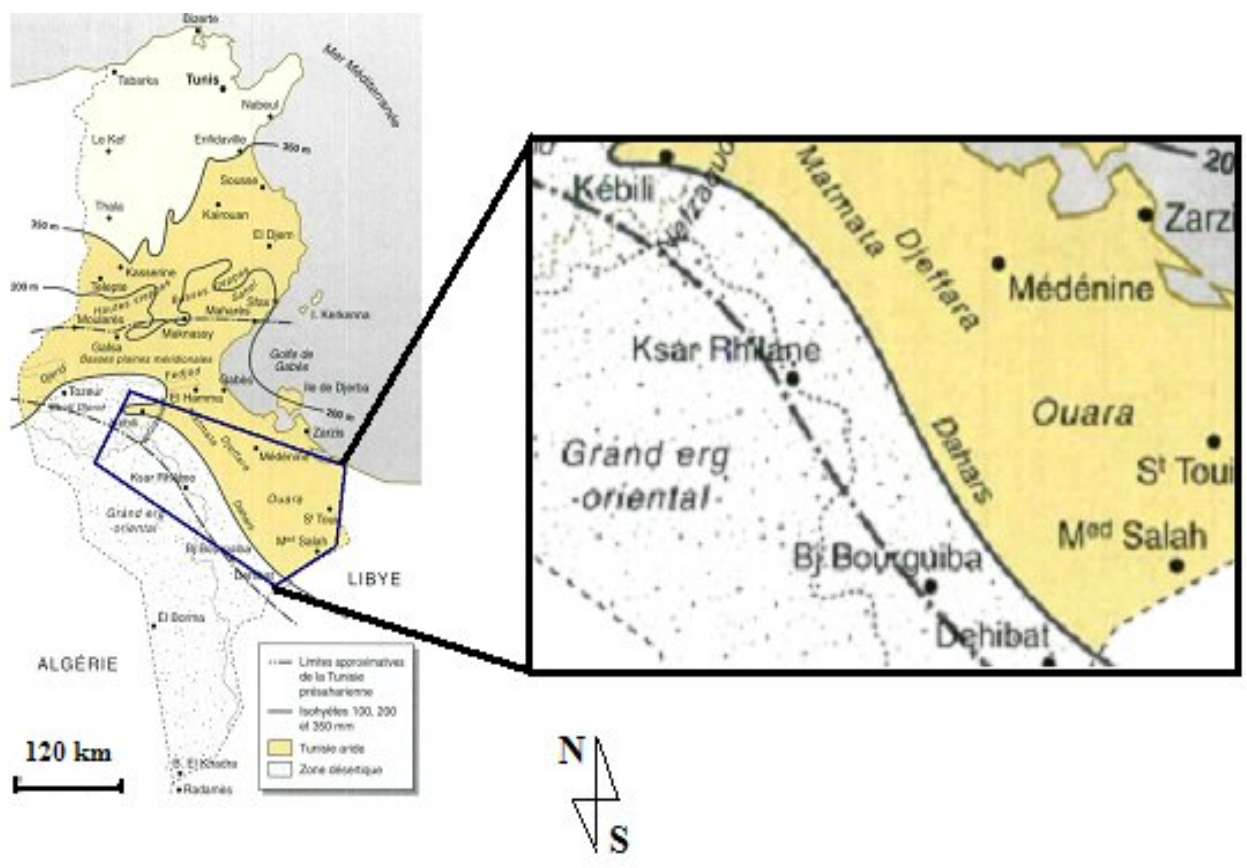

Figure 1. Localization of study area. 


\section{Camel herds and body measurements}

At the base of preliminary information collected from the national organizations for the Livestock Development (Office d'Elevage et des Pâturages, Commissariats Régionaux au Développement Agricole) and camel-breeder, five groups of Maghrebi camel have been identified in the southern Tunisian region. These groups included the Ourdhaoui Médenine (OM) reared by the community of Tawazins, the Ourdhaoui Tataouine (OT) reared by the community of Oudarna, the Guiloufi (GuiK), the Gueoudi (GueK) and the Merzougui (MK) reared in Kébili by the communities of Beni Guilouf, Ouled Gharib and Marazigues, respectively.

The access to camel herds at their grazing area was accomplished after the collaboration with national organizations for the Livestock Development of Médenine, Tataouine and Kébili. The identification of the general data of breeding (breed, colour, breeding practice...) was collected after conversation with camel-breeders and shepherds. A total of 304 not pregnant female camels aged from 6 to 14 years were studied by recording nine body measurements in a standing position using a ribbon meter. Body length (BL) was measured from the shoulder Pars Caudalis Tuberculi Majoris to the hip Tuber Ischiadicum. The neck length (NL) was also taken as the distance separated the attachment point of the neck at the thorax and the head. The thoracic girth (TG) was measured directly behind the sternal pad. The abdomen circumference (AC) was taken at level of the hump. The height at the hump ( $\mathrm{HH})$ was measured from the ground to the top end of the hump, the height at the withers (HW) was measured from the ground to the top end of the Vertebra thoracica 3, width at the shoulders (WS) was taken between the two shoulders, the anterior limb length
(ALL) was measured from the ground to the level of the shoulder and finally the tail length (TL) was determined from the point tail starting to the end of the rear vertebrae column.

\section{Statistical analyses}

To identify sources of variation, data from body measurements were analyzed using SAS package. The significant difference between means of body measurements was tested using Student-NewmanKeuls test. The correlations between the different measurements were assessed by calculating the correlation coefficient of Pearson. The Distance procedure was performed to obtain a distance matrix that was used as input to a subsequent clustering procedure. Frequencies distribution was calculated using Proc Freq. Results are expressed as mean ( \pm standard deviation). The level of significance was set at $\mathrm{P}<0.05$ in all analyses.

\section{Results \\ Body measurements}

Variability of all traits was less than $20 \%$ (Table 1). Tail length was the most variable trait with a coefficient of variation superior to $15 \%$. The coefficients of variation of the other measurements varied between $5 \%$ and $11 \%$ (Table 1 ).

Correlations between the various traits varied between 0.12 and 0.73 (Table 2). The highest correlation coefficients were found between height at the hump (HH) and height at the withers (HW) $(0.73 ; \mathrm{P}<0.001)$, between the thoracic girth (TG) and the abdominal circumference (AC) $(0.43 ; \mathrm{P}<0.001)$, between the body length (BL) and the neck length (NL) $\quad(0.38 ; \quad \mathrm{P}<0.001)$. The lowest positive correlation (0.12) was found between height at the hump $(\mathrm{HH})$ and body length. However, the tail length (TL) was negatively correlated with the abdominal circumference $\mathrm{AC}(-0.31 ; \mathrm{P}<0.001)$ and the height at the withers (HW) $(-0.12 ; \mathrm{P}<0.05)$.

Table 1. Mean, standard deviation (S.D), coefficient of variation (C.V) and variance analysis for 9 body measurements and effect of tribe's affiliation group of female Maghrebi camel in Southern Tunisia.

\begin{tabular}{llllll}
\hline Body measurements & Mean $(\mathrm{cm})$ & S.D & $C . V(\%)$ & $\mathrm{F}$ & Significance \\
\hline Body length & 140 & 11 & 7.64 & 9.4 & $* * *$ \\
Neck length & 101 & 7 & 7.40 & 2.28 & ns \\
Thoracic girth & 198 & 12 & 6.06 & 7.16 & $* * *$ \\
Abdominal circumference & 212 & 23 & 10.7 & 62.6 & $* * *$ \\
Height at the hump & 190 & 10 & 5.30 & 8.37 & $* * *$ \\
Height at the withers & 175 & 10 & 5.66 & 14.17 & $* * *$ \\
Width at shoulders & 50 & 5 & 9.24 & 7.58 & $* * *$ \\
Anterior limb length & 123 & 10 & 8.49 & 2.59 & $*$ \\
Tail length & 46 & 7 & 15.60 & 55.86 & $* * *$ \\
$* * *: P<0.001, *: P<0.05$, ns: $: P>0.05$. & & & & &
\end{tabular}


Table 2. Correlations between body measurements in female Maghrebi camel in Southern Tunisia.

\begin{tabular}{|c|c|c|c|c|c|c|c|c|}
\hline Maghrebi female camels $(n=304)$ & & & & & & & & \\
\hline & $\mathrm{NL}$ & TG & $\mathrm{AC}$ & $\mathrm{HH}$ & HW & WS & ALL & TL \\
\hline Body length (BL) & $0.38^{* * *}$ & $0.16^{* *}$ & $0.28^{* * * *}$ & $0.12^{*}$ & $-0.01^{\mathrm{ns}}$ & $0.11^{\mathrm{ns}}$ & $0.21^{* * *}$ & $-0.10^{\mathrm{ns}}$ \\
\hline Neck length (NL) & & $0.20^{* * *}$ & $0.06^{\mathrm{ns}}$ & $0.20^{* * *}$ & $0.09^{\mathrm{ns}}$ & $0.21^{* * *}$ & $0.28^{* * *}$ & $0.25^{* * *}$ \\
\hline Thoracic girth (TG) & & & $0.43^{* * *}$ & $0.31^{* * *}$ & $0.15^{*}$ & $0.17^{* *}$ & $0.07^{\mathrm{ns}}$ & $-0.03^{\mathrm{ns}}$ \\
\hline Abdominal Circumference ( AC) & & & & $0.41^{* * *}$ & $0.30^{* * *}$ & $0.13^{*}$ & $0.06^{\mathrm{ns}}$ & $-0.31^{* * *}$ \\
\hline Height at the hump $(\mathrm{HH})$ & & & & & $0.73^{* * *}$ & $0.34^{* * *}$ & $0.14^{*}$ & $0.01^{\mathrm{ns}}$ \\
\hline Height at the withers (HW) & & & & & & $0.25^{* * *}$ & $0.14^{*}$ & $-0.12^{*}$ \\
\hline Width at shoulders (WS) & & & & & & & $0.30^{* * *}$ & $0.28^{* * *}$ \\
\hline Anterior limb length (ALL) & & & & & & & & $0.05^{\mathrm{ns}}$ \\
\hline Tail length (TL) & & & & & & & & $1^{* * *}$ \\
\hline
\end{tabular}

There were high significant differences $(\mathrm{P}<0.001)$ between the five studied groups of Maghrebi camel, in the following measurements: the body length, thoracic girth, hump circumference, height at the hump, height at the withers, width at the shoulders and tail length. Body measurements according to the camel groups are summarized in Table 3. The body length of Gueoudi (Photo 1) and Guiloufi camel groups (Photo 2) was higher $(\mathrm{P}<0.05)$ than in Ourdhaoui Tataouine (Photo 4) and Ourdhaoui Médenine groups (Photo 5). The Merzougui group (Photo 3)

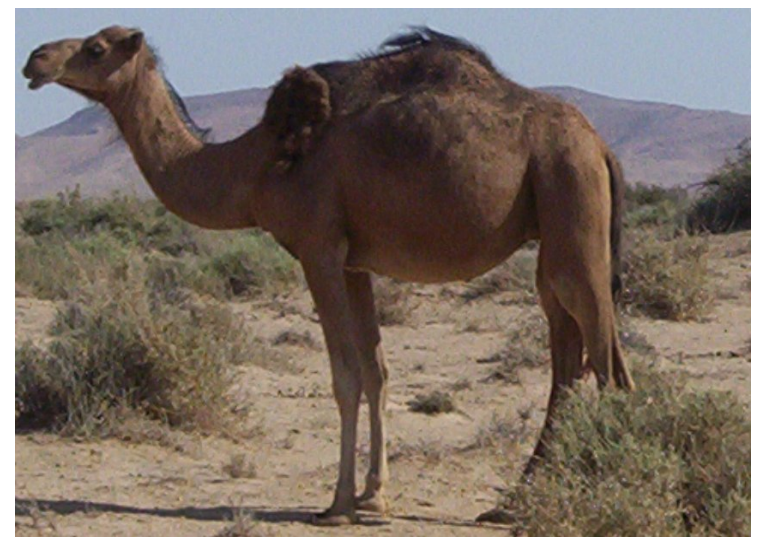

Photo 1. Gueoudi Maghrebi camel. El-Faouar, Rejim Maatoug regions at Kébili. occupied an intermediate position between the two groups. The thoracic girth was more important $(\mathrm{P}<0.05)$ in Gueoudi, Guiloufi, Ourdhaoui Tataouine and Merzougui camel groups than Ourdhaoui Médenine. The Gueoudi, Merzougui and Guiloufi groups exceeded $(\mathrm{P}<0.05)$ the Ourdhaoui group in the abdominal circumference. The Ourdhaoui Médenine group had the small size. The height at hump was more important $(\mathrm{P}<0.05)$ in Gueoudi, Guiloufi, Ourdhaoui Tataouine and Merzougui groups than Ourdhaoui Médenine.

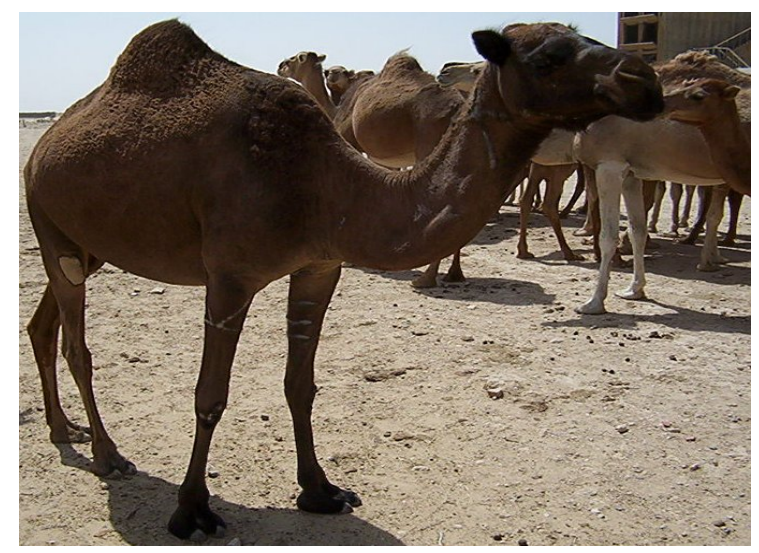

Photo 2. Guiloufi Maghrebi camel. Bazma, El Golâa, Bir Aguèreb regions at Kébili. 


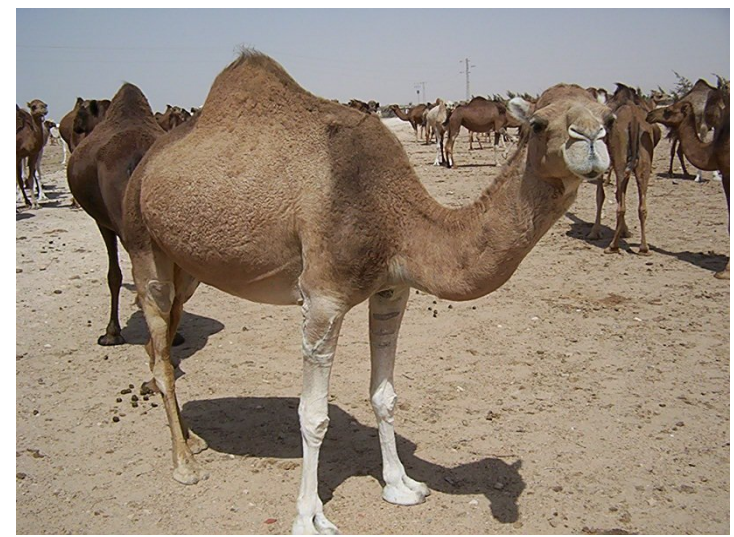

Photo 3. Merzougui Maghrebi camel. Douz, Nowyel regions at Kébili.

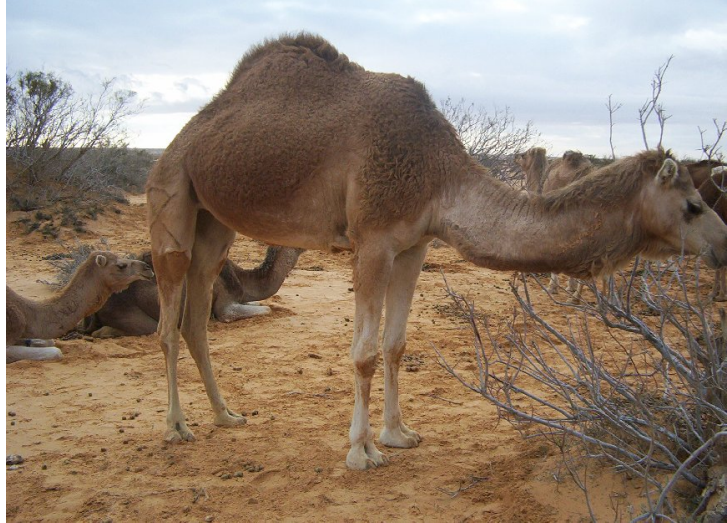

Photo 4. Ourdaoui Tataouine Maghrebi camel. Daghssen, Remada,Theheeba regions at Tataouine.

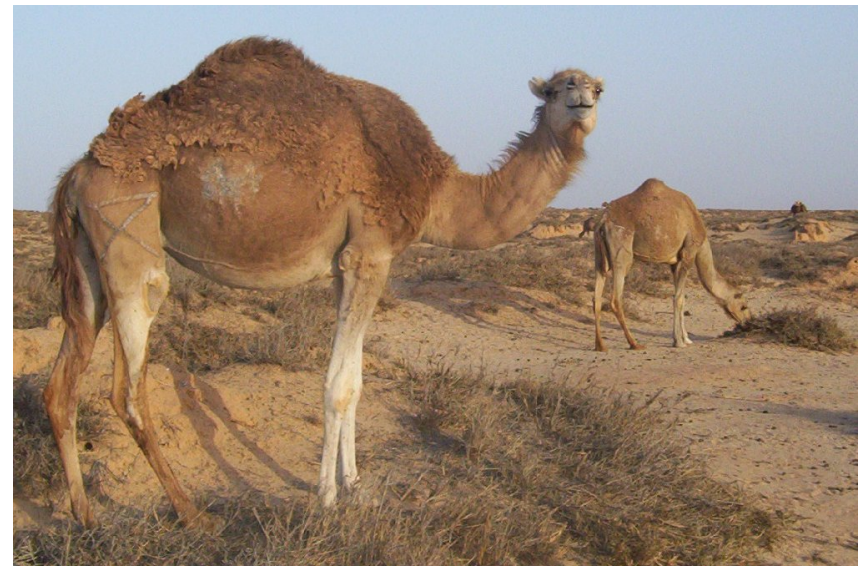

Photo 5. Ourdaoui Médenine Maghrebi camel.

Echoucha, El-Ouâra regions at Médenine.

Table 3. Body measurements (BM) of Gueoudi (GueK), Guiloufi (GuiK), Merzougui (MK), Ourdhaoui Tataouine (OT) and Ourdhaoui Médenine (OM) camel groups. ${ }^{\text {a,b,c }}$ Means within line with different superscript differ $(\mathrm{P}<0.05)$.

\begin{tabular}{llllll}
\hline Camel groups & \multicolumn{5}{l}{} \\
\hline BM $(\mathrm{cm})$ & GueK $(\mathrm{n}=34)$ & GuiK $(\mathrm{n}=38)$ & MK $(\mathrm{n}=28)$ & OT $(\mathrm{n}=97)$ & OM $(\mathrm{n}=107)$ \\
\hline BL & $147 \pm 6^{\mathrm{a}}$ & $143 \pm 10^{\mathrm{a}}$ & $142 \pm 6^{\mathrm{ab}}$ & $138 \pm 9^{\mathrm{bc}}$ & $136 \pm 13^{\mathrm{c}}$ \\
NL & $100 \pm 5$ & $103 \pm 8$ & $100 \pm 6$ & $99 \pm 8$ & $101 \pm 8$ \\
TG & $200 \pm 11^{\mathrm{a}}$ & $200 \pm 9^{\mathrm{a}}$ & $199 \pm 9^{\mathrm{a}}$ & $201 \pm 13^{\mathrm{a}}$ & $194 \pm 12^{\mathrm{b}}$ \\
$\mathrm{AC}$ & $233 \pm 8^{\mathrm{a}}$ & $226 \pm 11^{\mathrm{a}}$ & $228 \pm 13^{\mathrm{a}}$ & $217 \pm 19^{\mathrm{b}}$ & $193 \pm 19^{\mathrm{c}}$ \\
HH & $194 \pm 4^{\mathrm{a}}$ & $193 \pm 7^{\mathrm{a}}$ & $190 \pm 9^{\mathrm{a}}$ & $192 \pm 9^{\mathrm{a}}$ & $186 \pm 12^{\mathrm{b}}$ \\
HW & $182 \pm 6^{\mathrm{a}}$ & $177 \pm 6^{\mathrm{b}}$ & $176 \pm 8^{\mathrm{b}}$ & $177 \pm 7^{\mathrm{b}}$ & $170 \pm 12^{\mathrm{c}}$ \\
ALL & $126 \pm 4$ & $126 \pm 7$ & $122 \pm 5^{\mathrm{a}}$ & $121 \pm 15$ & $122 \pm 9$ \\
WS & $51 \pm 4^{\mathrm{a}}$ & $48 \pm 5^{\mathrm{b}}$ & $47 \pm 3^{\mathrm{b}}$ & $51 \pm 5^{\mathrm{a}}$ & $49 \pm 4^{\text {ab }}$ \\
TL & $38 \pm 3^{\mathrm{b}}$ & $41 \pm 6^{\mathrm{b}}$ & $39 \pm 5^{\mathrm{b}}$ & $49 \pm 5^{\mathrm{a}}$ & $50 \pm 6^{\mathrm{a}}$ \\
BL: Body length; NL: neck length; TG: thoracic girth; AC: abdominal circumference; HH: height at the hump; HW: height at the withers; WS: width at shoulders; ALL: anterior
\end{tabular}


Table 4. Distance matrix calculated between Maghrebi camel groups according to their body measurements.

\begin{tabular}{lllll}
\hline Camel groups & Geoudi & Guiloufi & Merzougui & Ourdhaoui Tataouine \\
\hline Geoudi & 0.000 & --- & --- & --- \\
Guiloufi & 3.085 & 0.000 & --- & -- \\
Merzougui & 3.594 & 2.874 & 0.000 & -- \\
Ourdhaoui Tataouine & 3.967 & 4.236 & 3.318 & 0.000 \\
Ourdhaoui Médenine & 6.378 & 5.150 & 4.364 & 4.282 \\
\hline
\end{tabular}

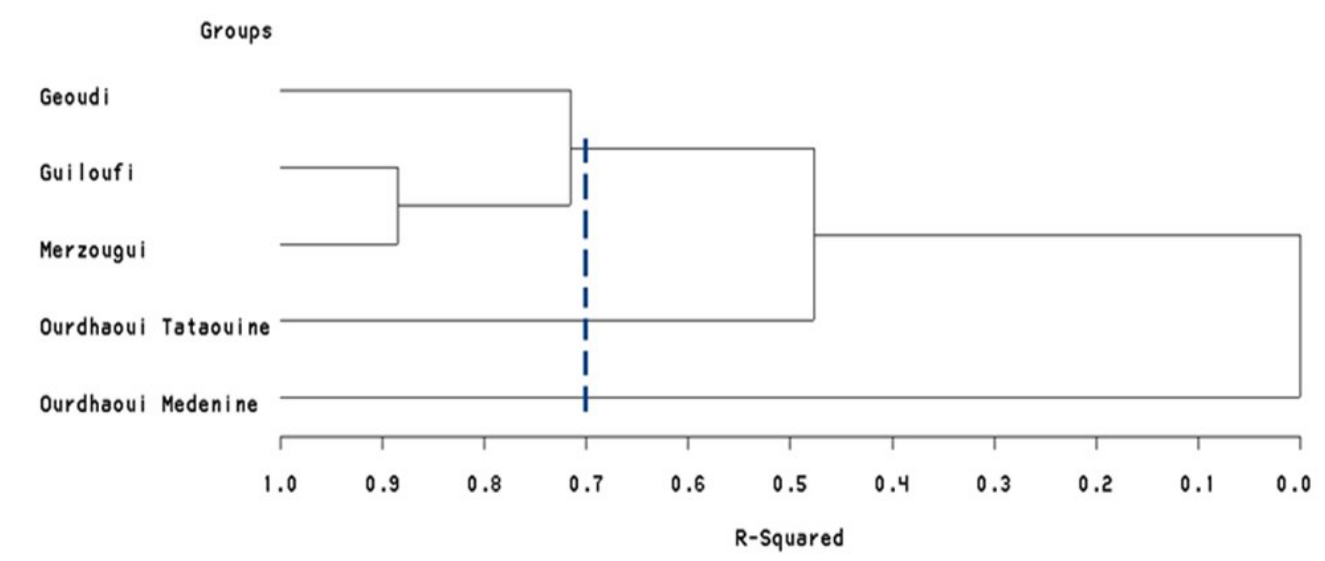

Figure 2. Hierarchical clustering versus R-Square values of Maghrebi camel groups according to 9 body measurements.

Results show that Gueoudi group exceeded $(\mathrm{P}<0.05)$ the all others groups in the height at the withers. The Ourdhaoui Tataouine, Guiloufi and Merzougui groups had a medium values but exceeding $(\mathrm{P}<0.05)$ the Ourdhaoui Médenine. The width at the shoulders was larger $(\mathrm{P}<0.05)$ in Ourdhaoui Tataouine and Gueoudi than Guiloufi and Merzougui camel groups. The Ourdhaoui Médenine group had a medium measurement. The Ourdhaoui group exceeded $(\mathrm{P}<0.05)$ Guiloufi, Merzougui and Gueoudi camel groups in the tail length.

The hierarchical classification of body measurements performed on five groups of the female Maghrebi camels was optimal with a partition within 3 classes which explained $70 \%$ of the variance (Table 4 and Figure 2).

A first class (A) included Geoudi, Guiloufi and Merzougui camel groups. They were characterized by the higher measurements of BL, NL, TG, AC, $\mathrm{HH}, \mathrm{HW}$ and ALL, but with the low measurements of TL and WS. A second class (B) gathered the group of the Ourdhaoui Tataouine which had the medium measurements of BL, NL, AC, ALL and TL. This class had higher measurements of the TG, HH, ALL and WS. The class of Ourdhaoui Médenine (C) was separated from the two others classes and had the low measurements of BL, TG, $\mathrm{AC}, \mathrm{HH}, \mathrm{HW}$ and WS, but with higher length of the neck and the tail (Table 5).

Table 5. Mean body measurements (BM) of the 3 clusters of the groups of female Maghrebi camels.

\begin{tabular}{llll}
\hline Classes & & & \\
\hline BM $(\mathrm{cm})$ & $\mathrm{A}(\mathrm{n}=100)$ & $\mathrm{B}(\mathrm{n}=97)$ & $\mathrm{C}(\mathrm{n}=107)$ \\
\hline $\mathrm{BL}$ & $144 \pm 8^{\mathrm{a}}$ & $138 \pm 9^{\mathrm{b}}$ & $136 \pm 13^{\mathrm{b}}$ \\
$\mathrm{NL}$ & $101 \pm 7^{\mathrm{a}}$ & $99 \pm 8^{\mathrm{b}}$ & $101 \pm 8^{\mathrm{a}}$ \\
$\mathrm{TG}$ & $200 \pm 10^{\mathrm{a}}$ & $201 \pm 13^{\mathrm{a}}$ & $194 \pm 12^{\mathrm{b}}$ \\
$\mathrm{AC}$ & $229 \pm 11^{\mathrm{a}}$ & $217 \pm 19^{\mathrm{b}}$ & $193 \pm 19^{\mathrm{c}}$ \\
$\mathrm{HH}$ & $192 \pm 7^{\mathrm{a}}$ & $192 \pm 9^{\mathrm{a}}$ & $186 \pm 12^{\mathrm{b}}$ \\
$\mathrm{HW}$ & $179 \pm 7^{\mathrm{a}}$ & $176 \pm 7^{\mathrm{b}}$ & $170 \pm 12^{\mathrm{c}}$ \\
$\mathrm{ALL}$ & $125 \pm 6^{\mathrm{a}}$ & $121 \pm 15^{\mathrm{b}}$ & $122 \pm 9^{\mathrm{b}}$ \\
WS & $49 \pm 4^{\mathrm{b}}$ & $51 \pm 5^{\mathrm{a}}$ & $49 \pm 4^{\mathrm{b}}$ \\
TL & $40 \pm 5^{\mathrm{c}}$ & $48 \pm 5^{\mathrm{b}}$ & $50 \pm 6^{\mathrm{a}}$ \\
a,b,c Means within line with different superscript differ (P<0.05). & &
\end{tabular}


Emir. J. Food Agric. 2013. 25 (8): 625-634

http://www.ejfa.info/

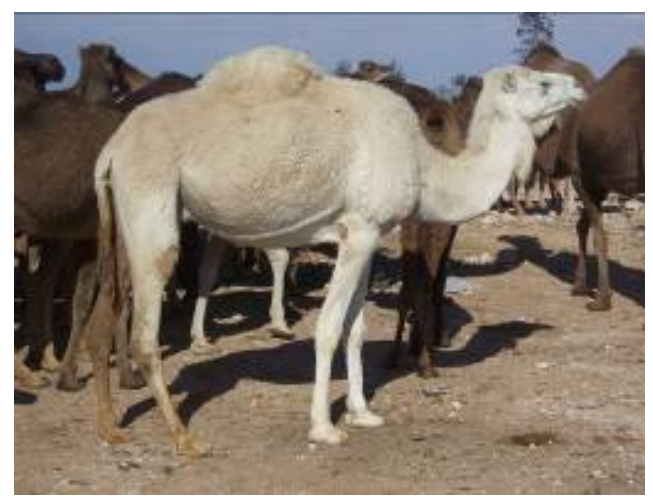

Photo 6. Nagga Chagra

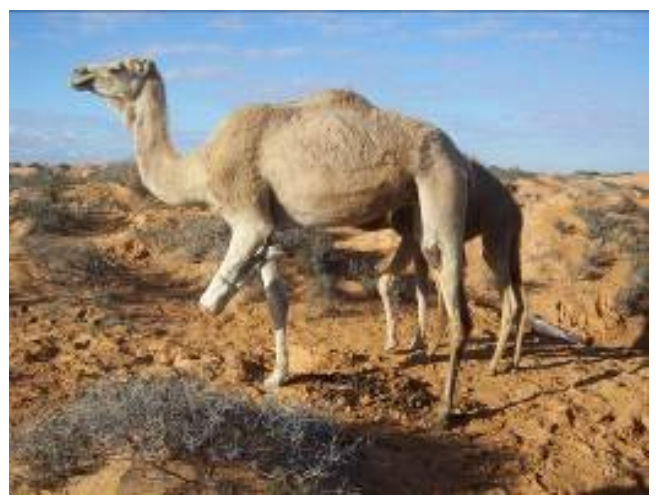

Photo 8. Nagga Safra

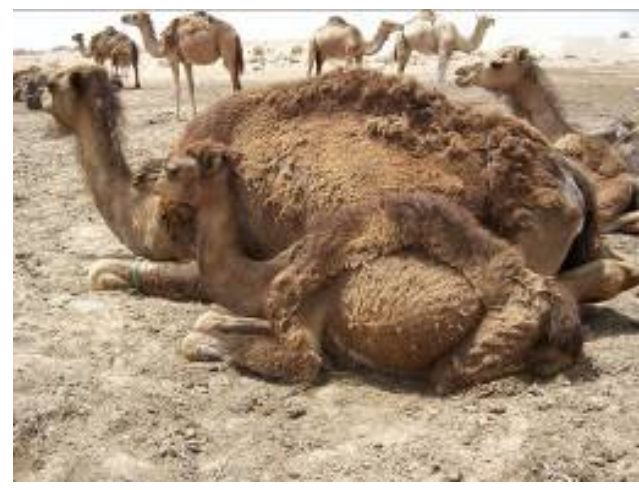

Photo 10. Nagga Hamra

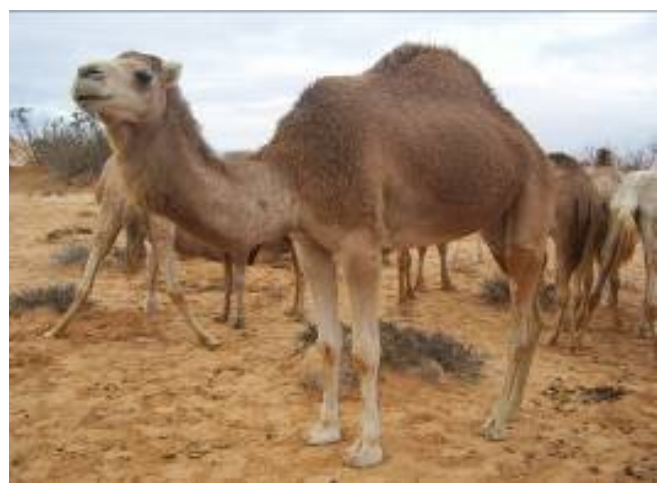

Photo 12. Nagga Chalfi (or Harcha)

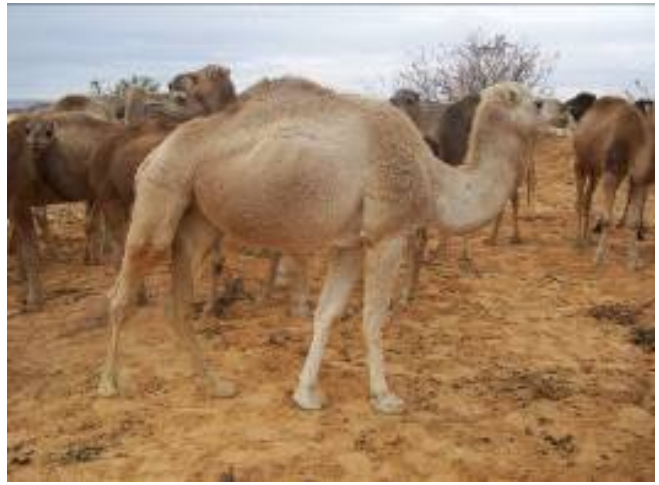

Photo 7. Nagga Chaâla

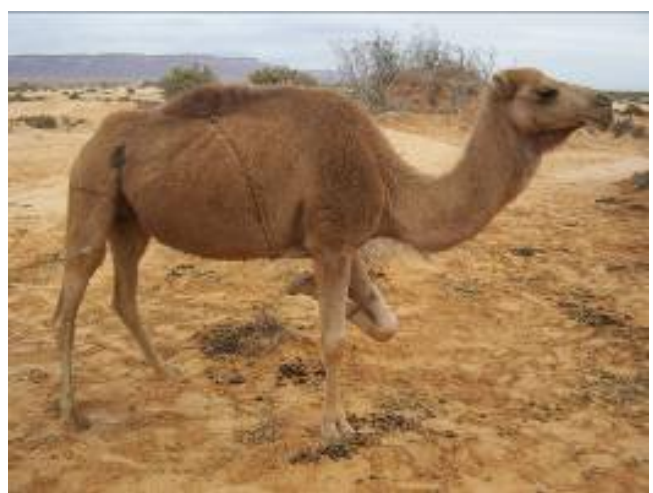

Photo 9. Nagga Hajla

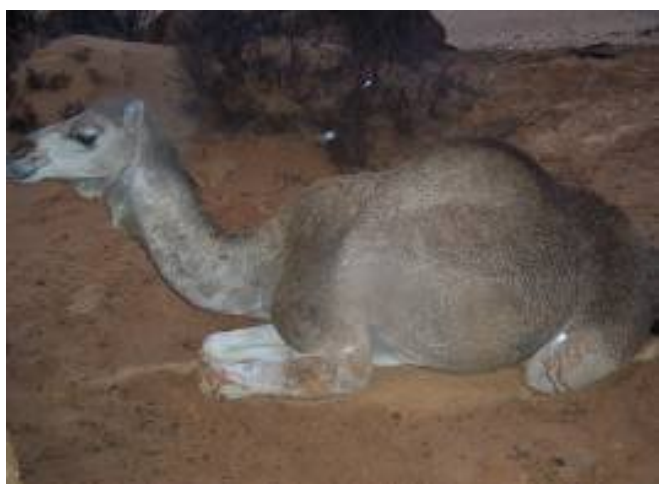

Photo 11. Nagga Zarga

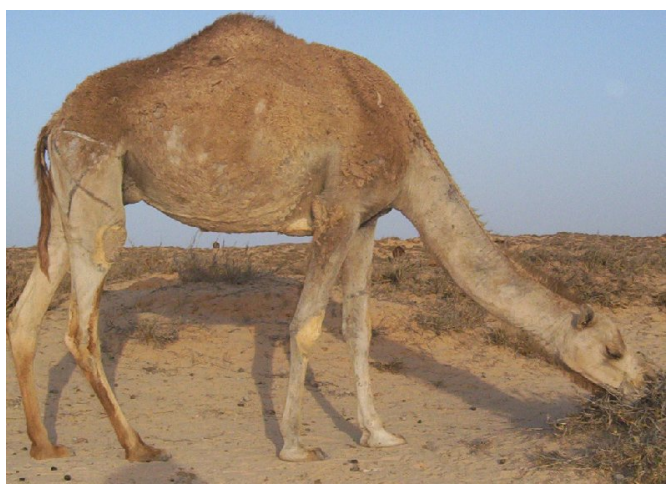

Photo 13. Nagga Kawar 


\section{Qualitative traits}

Our study revealed that the colour range of female Maghrebi camels is very heterogeneous. According to camel-breeders and shepherds, six vernaculars colours were described and varied between the white at the grey and namely, Chagra (white: 6.5\%, Photo 6), Chaâla (slightly white: 5.5\%, Photo 7), Safra (yellow: $28.9 \%$, Photo 8), Hajla (fawn: 8.6\%, Photo 9), Hamra (brown: 29.6\%, Photo 10) and Zarga (gray: $20.9 \%$, Photo $11)$.

The main type of hair in camels was rough $(97.7 \%)$, whereas the sleek hair was found only in some females $(2.3 \%)$. Often, the female camel with a rough hair is named Nagga Chalfi or Harcha (Photo 12), whereas that with a sleek hair is named Nagga Kawar (Photo 13). In fact, the Nagga Kawar is known by a good milk potential but the camel owners generally preferred Chalfi because she is very adapted to the harsh conditions in arid and desert regions.

\section{Discussion}

The present study provides body measurements in female Maghrebi camels. The body length measured in Maghrebi camel was less than those described for Gabbra camels in Somali, for Meghem, Gamra and Awadi Arabian camels in Saudi Arabia (Al Hazmi et al., 1994; Hülsebusch and Kaufman, 2002). Furthermore, the Mewari and the Jaisalmeri camel breeds had a more long body (Mehta et al., 2007) in comparison with Maghrebi camels. The Maghrebi camels showed similar measurements of thoracic girth in comparison with the Arabian camels (Al Hazmi et al., 1994), Mewari and Jaisalmeri camels (Mehta et al., 2007). The height at the withers was higher in the Maghrebi camel than in the Rendille camel, but smaller than those measured in Mewari, Jaisalmeri and Targui camels (Mehta et al., 2007; Oulad Belkhir et al., 2013). These differences between groups of dromedary in term of body measurements are genetically linked and revealing geographical distribution (Mahrous et al., 2011; Almathen et al., 2012). The height at the hump was low in Maghrebi camels compared to those described for Sahroaui and Targui in Algeria (Oulad Belkhir et al., 2013). The hump size varies according to the body condition score of the animal (Kamili et al., 2006). Indeed, the hump is the main fat storage form in camel representing on average $85 \%$ of the adipose tissue (Faye et al., 2001).

In our study, the comparisons reveal clear differences between five groups of Maghrebi camels. The groups of Gueoudi, Guiloufi and Merzougui showed the largest body measurements compared to the Ourdhaoui Tataouine and Ourdhaoui Médenine. The clustering of the different groups allowed describing three main classes of Maghrebi camel. These classes could be described: i) the big size camels from the areas of Kébili and which included the Geoudi, Guiloufi and Merzougui groups; ii) the medium size camels (Ourdhaoui Tataouine) from the regions of Tataouine; iii) the small size camels (Ourdhaoui Médenine) from the regions of Médenine. This grouping of Maghrebi camels revealed differences which are mainly linked to geographical distribution as it has been observed in previous study (Ould Ahmed et al., 2010).

The study of hair revealed that the colour of Maghrebi camel groups range was very heterogeneous and six vernaculars colours have been revealed for the five studied groups. Those results differ from that have been revealed for Rendille camels of Kenya known by two roan colours, namely wersi and borakhan and two solid colours surwa and gatab hass. The colour gomboch could not be found in the sample but might be identical to gatab hass, as it is described as a light yellow. The new colours account for less than $0.8 \%$ of the total sample while the colours bori (brown), dakhan (white) and eidimo (dark fawn) together add up to $67.4 \%$ of the all colours within the sample (Adams and Kaufmann, 2003). Otherwise, each breed of Arabian camel has its own colour: the Meghem breed has black hair, the Sawahli breed is light and the Awadi breed darken in the hump; while the Gamra breed is whiter than the others (Al Hazmi et al., 1994). Accordingly, Abdalla and Faye (2012) described twelve different colors in camel breeds from Saudi Arabia.

\section{Conclusion}

Phenotypical description of Maghrebi camels according to their tribal affiliation in southern Tunisia could be a first contribution for classification of the different groups of camel, and for valorising their genetic biodiversity. A clear description of camel population is an important step, especially with current changes in their farming systems (settlement, intensification, indoor feeding systems, implementation around the towns, etc.,). For this reason, the present study limited to the body traits of Maghrebi camels in according to their tribal affiliation would be an opportunity to underline the richness of this emblematic animal whatever their social rank or the place where they 
are living. The results reported the existence of subgroups among the local population. However, for further refining this study, it is necessary to consider the performance characteristics (meat production, milk productivity and numerical productivity) and variation analyze in DNA fingerprinting, with the perspective to lead to a kind of standards Maghrebi camels.

\section{Acknowledgements}

Authors are grateful to the "Office d'Elevage et des Pâturages" and "Commissariats Régionaux au Développement Agricole" technicians in southern Tunisia for their help in the realization of this work. Special thanks are expressed to the peoples of the Merazig, Beni Guilouf, Ouled Gharib, Oudarna Tataouine, Tawazin and Rebaia tribes for their selfless support.

\section{References}

Abdallah, H. R. and B. Faye. 2012. Phenotypic classification of Saudi Arabian camel (Camelus dromedarius) by their body measurements. Emir. J. Food Agric. 24:272280.

Adams, M. and B. A. Kaufmann. 2003. Tierhalter und lokales Wissen, Indigene Charakterisierung lokaler Kamelpopulationen und Zuchtmaßnahmen von Nomaden in Nordkenia, Kommunikation und Beratung, Sozialwissenschaftliche Schriften zur Landnutzung 53, Margraf Verlag, Weikersheim, Deutschland.

Al Hazmi, M.A., A. M. Ghandour and M. ElGohar. 1994. A Study of the Biometry of Some Breeds of Arabian Camel (Camelus dromedarius) in Soudi Arabia. JKAU: Sci. 6:87-99.

Almathen, F., J. Mwaracharo and O. Hanotte. 2012. Genetic diversity and relationships of indigenous Saudi Arabia camel (Camelus dromedarius) populations. In: E. H. Johnson et al. (Eds.), pp. 40-41. Proc. 3rd ISOCARD Conference, $29^{\text {th }}$ January- $1^{\text {st }}$ February, 2012, Mascate (Sultanate of Oman).

Belloumi, M. and M. S. Matoussi. 2006. A Stochostic Frontier Approach for Measuring Technical Efficiencies of Date Farms in Southern Tunisia. Agric. Res. Econ. Rev. 35/32:285-298.

Ben Salah, R., M. Hammadi and M. H. Yahyaoui. 2009. Genetic diversity of Tunisian Dromedary (Camelus dromedarius) as revealed by microsatellites. The Second Conference of the International Society of Camelid Research and Development Djerba, Tunisia: $11^{\text {th }}-14^{\text {th }}$ March, 2009, Abstract book, 210:213.

FAO, UNDP, 2000. World Watch List (Ed. B. D. Scherf.) FAO, Rome, Italy.

Faye, B., H. Abdallah, F. Almathen, B. Harzallah and S. Al-Mutairi. 2011. Camel biodiversity. Camel phenotypes in the Kingdom of Saudi Arabia, Camel Breeding, Protection and Improvement Center, project UTF/SAU/021/SAU, FAO Publ., Riyadh (Saudi Arabia), p.78.

Faye, B., M. Bengoumi, A. Cleradin, A. Tabarani and Y. Chilliard. 2001. Body condition score in dromedary camel: a tool for management of reproduction. Emir. J. Food Agric. 13:1-6.

Hammadi, M. 2003. Caractérisation, modulation nutritionnelle et implication du système IGF dans la fonction de reproduction chez la chamelle (Camelus dromedarius). Ph.D. FUSA GX Belgique, pp.160.

Hülsebusch, C. G. and B. A. Kaufman. 2002. Camel Breeds and Breeding in Northern Kenya -An account of local camel breeds of Northern Kenya and camel breeding management of Turkana, Rendille, Gabra, and Somali pastoralists. Kenya Agricultural Research Institute, Nairobi- Kenya.

Ishag, I. A., M. O. Eissa and M. K. A. Ahmed. 2011. Phenotypic characteristics of Sudanese camels (Camelus dromedarius). Livestock Res. Rural Dev. 23:99.

Kamili, A., M. Bengoumi and B. Faye. 2006. Assessment of body condition and body composition in camel by barymetric measurements. J. Camel Practice Res. 13:6772.

Mahrous, K. F., H. A. Ramadan, S. H. AbdelAziem, M. Abd-El Mordy and D. M. Hemdan. 2011. Genetic variations between camel breeds using microsatellite markers and RAPD techniques. J. Appl. Biosci. 39:2626-2634.

Mehta, S. C., B. Bhardwaj and M. S. Sahni. 2007. Status and conservation of Mewari and Jaisalmeri camels in India. AGRI 40:87-101.

Oulad Belkhir, A., A. Chehma and B. Faye. 2013. Phenotypic variability of two principal 
Algerian camel's populations (Targui and Sahraoui). Emir. J. Food Agric. 25(3):231-237.

Ould Ahmed, M., F. Ben Salem, S. Bedhiaf, B. Rekik and M. Djemali. 2010. Genetic diversity in Tunisian dromedary (Camelus dromedarius) populations using microsatellite markers. Livestock Sci. 132:182-185.

Sghaier, M. and M. Moslah. 2004. Importance du dromadaire en Tunisie et commercialisation de ses produits. Session de formation sur l'élevage camelin, Institut des Régions Arides, Médenine, 18-20 février.

Wardeh, M. F., A. A. Zaied and H. S. Horier. 1991. Camel breeds types in Arab Africa. Proceedings of the International Conference on Camel Production and Improvement, 10-13 December, 1990, Tobruk, Libya pp.126-145. 